\title{
The evolution of ischemic spinal cord injury in function, cytoarchitecture, and inflammation and the effects of adenosine $A_{2 A}$ receptor activation
}

T. Brett Reece, MD

David 0. Okonkwo, MD, $\mathrm{PhD}^{\mathrm{b}}$

Peter I. Ellman, MD ${ }^{a}$

Patrick S. Warren, BS ${ }^{a}$

Robert L. Smith, MD

A. Stewart Hawkins ${ }^{\text {b }}$

Joel Linden, $\mathrm{PhD}^{\mathrm{c}}$

Irving L. Kron, MD

Curtis G. Tribble, MD

John A. Kern, MD ${ }^{\mathrm{a}}$
From the Departments of Surgery ${ }^{\mathrm{a}}$ and Neuroscience $^{\mathrm{b}}$ and the Cardiovascular Research Center, ${ }^{c}$ University of Virginia Health System, Charlottesville, Va.

This study was funded by the Frank and Marion Falk Research Trust and by National Institutes of Health grant RO1 NF03949G.

Read at the Eighty-fourth Annual Meeting of The American Association for Thoracic Surgery, Toronto, Ontario, Canada, April 25-28, 2004.

Received for publication April 23, 2004; revisions received Aug 8, 2004; accepted for publication Aug 10, 2004.

Address for reprints: T. Brett Reece, MD, Department of Surgery, University of Virginia Health System, PO Box 801359, MR4 Building, Room 3116, Charlottesville, VA 22908 (E-mail: tbr5q@ virginia.edu).

J Thorac Cardiovasc Surg 2004;128:925-32 $0022-5223 / \$ 30.00$

Copyright $\odot 2004$ by The American Association for Thoracic Surgery

doi:10.1016/j.jtcvs.2004.08.019
Objective: Spinal cord ischemia/reperfusion injury involves multiple factors that may be modulated by adenosine $\mathrm{A}_{2 \mathrm{~A}}$ receptor activation. This study defines injury progression in terms of function, cytoarchitecture, and inflammation and assesses whether adenosine $\mathrm{A}_{2 \mathrm{~A}}$ receptor activation by ATL-146e limits injury progression.

Methods: Mature swine were divided into 3 groups: sham thoracotomy, IR (30 minutes of ischemia followed by reperfusion), and ATL (ischemia/reperfusion with ATL-146e administration for the first 3 hours of reperfusion). Subgroups were killed at $0,3,6,12,24$, and 48 hours after reperfusion. Function was followed up with Tarlov scores. Spinal cord tissue was evaluated for neuronal viability, microtubule-associated protein-2 immunohistochemistry, and neutrophil sequestration (myeloperoxidase assay). Spinal cord tissue, cerebrospinal fluid, and serum were evaluated for tumor necrosis factor- $\alpha$ by enzyme-linked immunosorbent assay.

Results: Function was significantly impaired at 24, 36, and 48 hours in the IR group compared with the sham and ATL groups $(P<.05)$. Neuronal viability and microtubule-associated protein-2 staining were significantly preserved in the sham and ATL groups compared with the IR group at 24 and 48 hours $(P<.05)$. Spinal cord myeloperoxidase levels were significantly higher in the IR group than in the sham and ATL groups at 24 and 48 hours. Although negligible in serum and cerebrospinal fluid, tumor necrosis factor- $\alpha$ levels in the spinal cord peaked significantly higher in the IR group compared with the sham and ATL groups at 6 and 24 hours $(P<.05)$.

Conclusions: Spinal cord ischemia/reperfusion induced changes in neutrophil sequestration, microtubule-associated protein-2 expression, and neuronal viability within 24 hours of reperfusion. Spinal cord tumor necrosis factor- $\alpha$ increased significantly by 6 to 12 hours after reperfusion. Adenosine $A_{2 A}$ receptor activation attenuates spinal cord inflammation, which may be critical for the preservation of neuronal function and cytoarchitecture after ischemia/ reperfusion. 


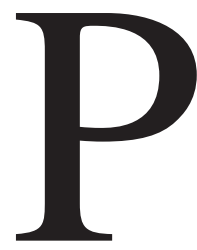

araplegia remains a significant risk for up to $20 \%$ of patients undergoing thoracic and thoracoabdominal aortic interventions. ${ }^{1}$ Although neuroprotective strategies for these patients are emerging, no pharmacologic interventions have been adequate for use in patients to prevent ischemic spinal cord injury. ${ }^{2}$

Previous studies have suggested that adenosine $A_{2 A}$ receptor activation may modulate several aspects of spinal cord ischemia/reperfusion (IR) injury. $A_{2 A}$ activation suppresses the inflammatory response to traumatic brain injury by suppressing leukocyte recruitment and by reducing cytokine release, most notably tumor necrosis factor (TNF)- $\alpha$ and interleukin-1. Spinal cord IR injury involves apoptotic death of neurons and white matter damage after injury, which can be further exacerbated by secondary inflammation. ${ }^{3}$ Adenosine $\mathrm{A}_{2 \mathrm{~A}}$ receptor-mediated suppression of inflammation may also limit this process of neuronal degeneration.

Previous studies using ATL-146e to activate the adenosine $\mathrm{A}_{2 \mathrm{~A}}$ receptor in animal models have shown that systemic adenosine $\mathrm{A}_{2 \mathrm{~A}}$ receptor activation can prevent functional impairment after temporary aortic occlusion. ${ }^{4-7}$ Other studies suggested that adenosine $\mathrm{A}_{2 \mathrm{~A}}$ receptor activation reduced systemic TNF- $\alpha$ levels and preserved spinal cord histology within the first 48 hours. ${ }^{8}$ However, the progression of spinal cord IR injury with respect to function, local and regional inflammation, and cytoarchitecture has not been examined. Moreover, the effect of adenosine $\mathrm{A}_{2 \mathrm{~A}}$ receptor activation on spinal cord IR injury progression is not known.

In this study, we evaluated the effect of adenosine $A_{2 A}$ receptor activation on the progression of spinal cord IR injury in terms of inflammation, neuronal cytoarchitecture, and function. We attempted to define the progression of cytoarchitectural damage over the first 48 hours by using neuronal viability scoring and microtubule-associated protein-2 (MAP-2) staining, a sensitive marker of ischemic neuronal injury. ${ }^{9}$ Additionally, we defined the progression of the local inflammatory response by focusing on neutrophil sequestration and TNF- $\alpha$ concentration, not only systemically in serum, but also regionally in cerebrospinal fluid (CSF) and locally in neuronal tissue. Finally, we observed a group of treated animals for 1 week after injury to determine whether the benefit in motor function is preserved over time.

\section{Methods}

All protocols were reviewed and approved by the Animal Care and Use Committee of the University of Virginia before the study began. All animals received humane care in compliance with the "Guide for the Care and Use of Laboratory Animals" (Institute of Laboratory Animal Resources, Commission on Life Sciences, National Research Council, 1996).
Mature domestic swine were separated into 3 groups. Sham, ATL-treated, and IR control groups underwent the following procedures before they were killed at specific time points for procurement of serum, CSF, and tissue.

\section{Procedures}

Domestic pigs were anesthetized with intramuscular ketamine (50 $\mathrm{mg} / \mathrm{kg}$ ) and xylazine $(1 \mathrm{mg} / \mathrm{kg})$. Pigs were intubated before connection to a volume ventilator (respiratory rate of 14 breaths/min and tidal volume of $250 \mathrm{~mL}$ ). Anesthesia was maintained with vaporized halothane. The arterial pressure was monitored with a pressure transducer (Hewlett-Packard, Palo Alto, Calif). Maintenance fluids were given at $100 \mathrm{~mL} / \mathrm{h}$. The animals' temperatures were maintained at $36^{\circ} \mathrm{C}$ for the procedure by using a heating pad.

Through a left lateral thoracotomy, the distal aortic arch and descending aorta was exposed. After systemic heparinization (heparin sulfate $200 \mathrm{U} / \mathrm{kg}$ ), a crossclamp was placed on the descending aorta distal to the left subclavian artery takeoff. The crossclamp was left in place for 30 minutes before the distal aorta was reperfused in the IR control animals. After reperfusion and hemostasis, the chest was closed. The animals were then allowed to emerge from anesthesia. Sham animals underwent the entire procedure except for the aortic occlusion. ATL-146e-treated animals (ATL group) underwent the IR procedure in addition to ATL-146e $\left(0.06 \mu \mathrm{g} \cdot \mathrm{kg}^{-1} \cdot \mathrm{min}^{-1} \mathrm{IV}\right)$ beginning 10 minutes before reperfusion and continuing for 3 hours. This dose of ATL was established in previous studies as optimal for ischemic spinal cord preservation. ${ }^{6}$

The animals were killed at specific times of reperfusion. Eight animals in each group at each time point were killed at the onset of reperfusion (sham and IR only) and then at 3, 6, 12, 24, and 48 hours after reperfusion $(n=136)$. Four more ATL animals were observed for 7 days to evaluate for any functional decompensation.

\section{Functional Assessment}

Functional status was graded by a blinded observer using the Tarlov scale. ${ }^{10}$ Scores range from 0 to 5 and are based on hind limb movement. No hind limb movement meant a score of 0 . Some movement meant a score of 1 . Animals able to sit with assistance were graded as 2. Animals able to sit alone received a score of 3 . Animals with an unsteady gait received a score of 4 . Animals with a normal gait received a score of 5. Functional scores were taken at $12,24,36$, and 48 hours. The 7-day survivors were graded once a day after the first 48 hours for the final 5 days.

\section{Tissue}

At the given time points, the animals were again anesthetized with ketamine and xylazine. Serum and CSF samples were obtained. After animals were killed, the left side of the chest was reopened. The descending aorta was excised to confirm that the crossclamp occluded the highest spinal artery. Any animal clamped below this branch was excluded from the study, regardless of group, because this critical spinal vessel can potentially preserve blood flow to the spinal cord. Next, the lumbar spinal cord was extracted to be fixed for histology and flashfrozen for molecular studies. 


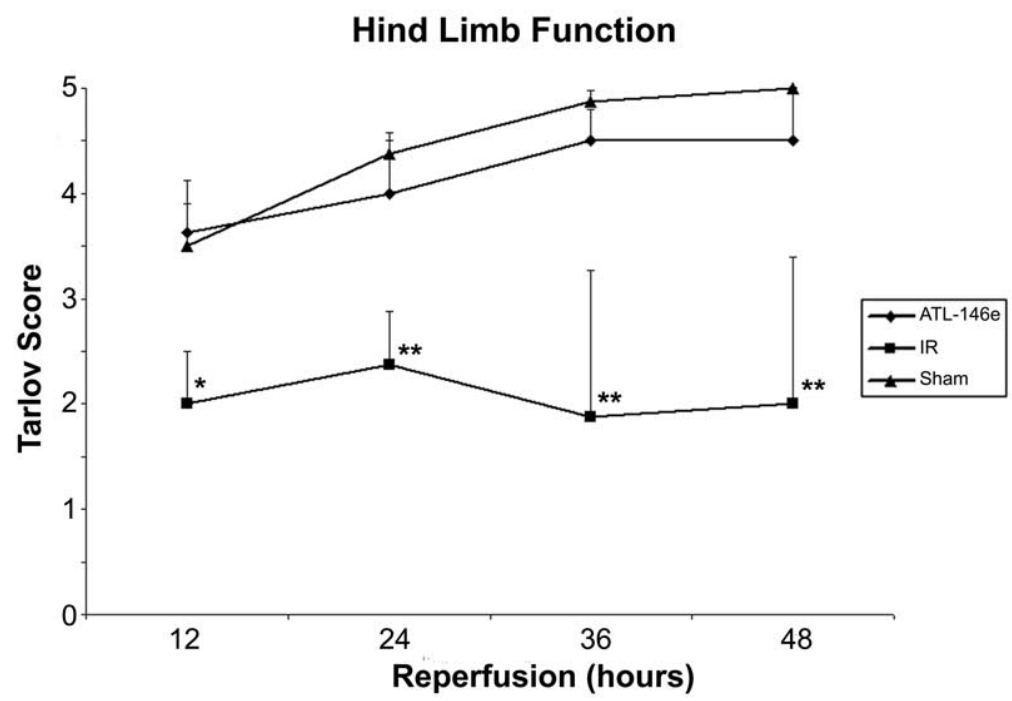

Figure 1. Hind limb function in the Tarlov scale over the first 48 hours of reperfusion. ${ }^{*} \boldsymbol{P}<.05$ compared with sham; ${ }^{* *} P<.01$ compared with both sham and ATL. IR, Ischemia/reperfusion.

\section{Myeloperoxidase Activity}

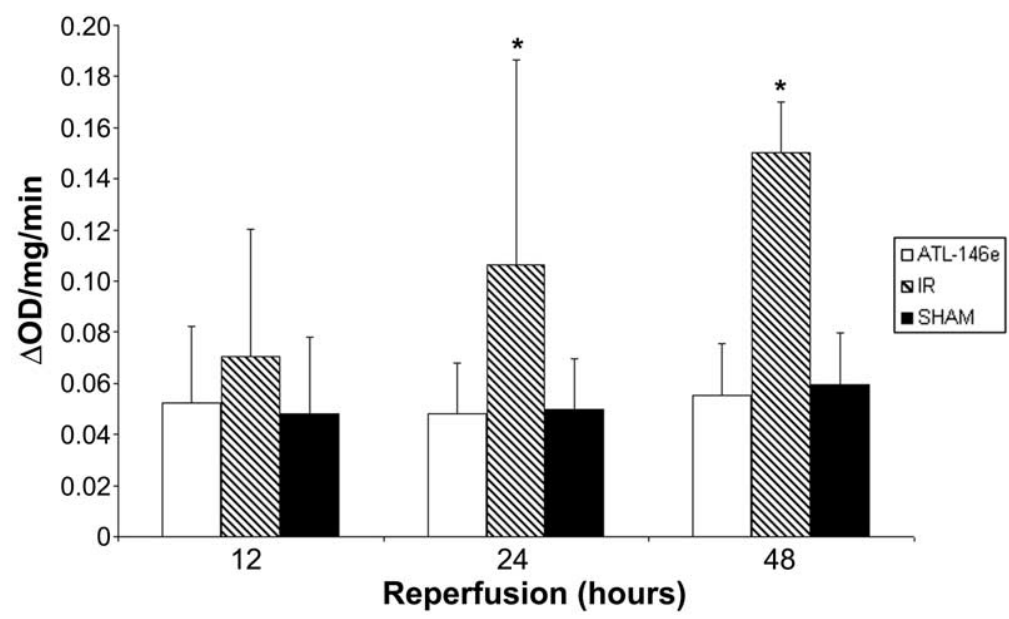

Figure 2. Myeloperoxidase activity in spinal cord tissue among the ATL-146e, sham, and ischemia/reperfusion (IR) groups at 12, 24, and 48 hours of reperfusion. ${ }^{*} P<.015$ compared with the sham and ATL groups. $\triangle O D$, Change in absorbance.

\section{Tumor Necrosis Factor- $\alpha$}

Lumbar spinal cord lysate was generated from a minimum of $5 \mathrm{mg}$ of tissue sample in Triton X-100 lysis buffer (Sigma-Aldrich Corp, St Louis, Mo) by using a tissue homogenizer (Fisher Scientific International, Pittsburgh, $\mathrm{Pa}$ ). The lysis buffer consisted of $1 \%$ Triton $\mathrm{X}-100,20 \mathrm{mmol} / \mathrm{L}$ Tris (pH 7.4; Sigma-Aldrich), $150 \mathrm{mmol} / \mathrm{L} \mathrm{NaCl}$ (Sigma-Aldrich), $1 \mathrm{mmol} / \mathrm{L}$ ethylenediaminetetraacetic acid (SigmaAldrich), leupeptin $2 \mu \mathrm{g} / \mathrm{mL}$ (Roche Diagnostics Corp, Indianapolis, Ind), pepstatin $0.7 \mu \mathrm{g} / \mathrm{mL}$ (Roche), chymostatin $100 \mu \mathrm{mol} / \mathrm{L}$ (Roche), and antipain $100 \mu \mathrm{mol} / \mathrm{L}$ (Roche). After centrifuging at 10,000 RPM at $0^{\circ} \mathrm{C}$ for 10 minutes, the supernatant was aspirated and frozen. TNF- $\alpha$ levels of spinal cord tissue lysates, CSF, and serum were determined by a commercially available enzyme-linked immunosorbent assay (ELISA) kit (Pierce Biotechnology Inc, Rockford, Ill) according to the manufacturer's protocols. All samples were tested in duplicate and averaged. The ELISA kit sensitivity for TNF- $\alpha$ was 20 $\mathrm{pg} / \mathrm{mL}$. All readings were performed on an MRX II absorbance reader (DYNEX Technologies Inc, Chantilly, Va). The TNF- $\alpha$ concentration was expressed in picograms per milliliter.

\section{Myeloperoxidase}

Neutrophil sequestration in the spinal cord was quantified with a myeloperoxidase (MPO) assay. Spinal cord tissue that had been 


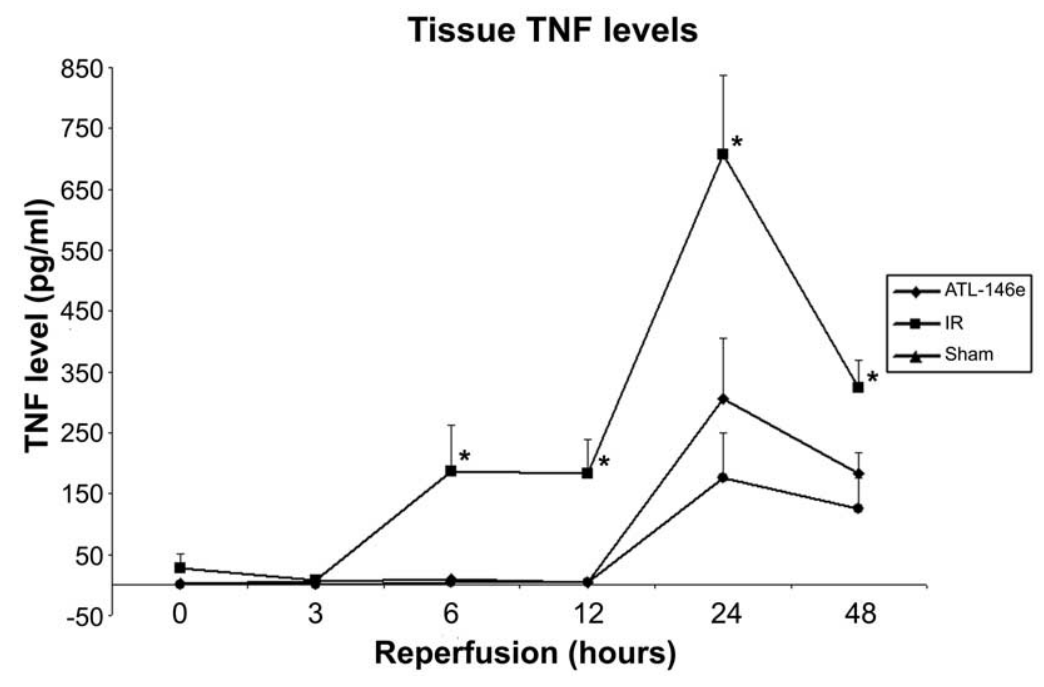

Figure 3. Spinal cord tumor necrosis factor (TNF)- $\alpha$ among the ATL-146e, sham, and ischemia/reperfusion (IR) groups over the first 48 hours of reperfusion. ${ }^{*} P<.01$ compared with both sham and ATL.

flash-frozen at harvest was stored at $-80^{\circ} \mathrm{C}$. The tissue was resuspended in $50 \mathrm{mmol} / \mathrm{L} \mathrm{KPO}_{4}(\mathrm{pH} \mathrm{7.4)}$ ) and then homogenized for 30 seconds at $4^{\circ} \mathrm{C}$. The solution was centrifuged for 15 minutes at 15,000g (Sorvall RC-5b Refrigerated Superseed Centrifuge; Kendro Labor Products, Newton, Conn). The supernatant was discarded. Next, the pellet was resuspended in 10 vol of $0.5 \%$ hexadecyltrimethylammonium bromide (HTAB) in $50 \mathrm{mmol} / \mathrm{L}$ $\mathrm{KPO}_{4}$ (pH 6.4) before a second homogenization of 90 seconds at $4^{\circ} \mathrm{C}$. The solution underwent sonication and 3 freeze/thaw cycles (liquid nitrogen and $37^{\circ} \mathrm{C}$ circulating bath). The solution was centrifuged for a second time at $15,000 \mathrm{~g}$ for 15 minutes. Then, 15 $\mathrm{mL}$ of supernatant was combined with $135 \mathrm{~mL}$ of assay buffer $(10$ $\mathrm{mg}$ of $o$-dianisidine in $1 \mathrm{~mL}$ of deionized water, $100 \mu \mathrm{L}$ of $\mathrm{H}_{2} \mathrm{O}_{2}$, and $8.9 \mathrm{~mL}$ of $50 \mathrm{mmol} / \mathrm{L}_{\mathrm{KPO}_{4}}[\mathrm{pH} 6.0]$ ) incubated at room temperature. Absorbance at $460 \mathrm{~nm}$ was measured over 2 minutes by spectrophotometry (MRX Revelation Plate Reader; Dynex Technologies, Inc, Chantilly, Va). Protein concentrations were determined in each sample by using the Coomassie Plus Protein Assay (Bio-Rad, Hercules, Calif). MPO activity was then expressed as a change in absorbance $(\Delta \mathrm{OD})$ per milligram protein per minute.

\section{Neuronal Viability}

Five-micrometer sections of formalin-fixed samples were stained with hematoxylin and eosin. Semiserial sections from the midthoracic spinal cord were counted in blinded fashion for the number of viable ventral horn motor neurons by using standard criteria. The mean number of intact motor neurons was quantitated for comparison.

\section{MAP-2 Immunohistochemistry}

Ten-micrometer sections of formalin-fixed samples were mounted on slides and deparaffinized in xylenes and progressive alcohol rinses. In preparation for immunocytochemistry, sections were processed by using a temperature-controlled microwave antigenretrieval approach described previously in detail. ${ }^{11}$ Endogenous peroxidase was blocked by incubation in a solution of $1.65 \% \mathrm{H}_{2} \mathrm{O}_{2}$ in $0.025 \%$ Triton $\mathrm{X}$ in Tris-buffered saline (TBS). Sections were incubated overnight in mouse anti-MAP-2 antibody (clone MT01; Abcam Ltd, Cambridge, United Kingdom) at a dilution of 1:100 in TBS with $1 \%$ bovine serum albumin before they were rinsed in TBS/Triton $\mathrm{X}$ and incubated for 2 hours in biotinylated anti-mouse immunoglobulin G (1:200; Vector, Burlingame, Calif) in TBS with $1 \%$ bovine serum albumin. After incubation in an avidin-biotin-peroxidase complex (ABC standard Elite kit; Vector; dilution of 1:100), and sections were processed for visualization of the immunohistochemical complex by $0.05 \%$ diaminobenzidine (Sigma-Aldrich) and $0.01 \%$ hydrogen peroxide.

The percentage of gray matter stained positively for MAP-2 within injured spinal cord was quantified and statistically compared among treatment groups and control animals. Semiserial spinal cord sections reacted for MAP-2 were examined with a microscope interfaced with a charge-coupled device digital camera and computer image analysis system (VisionGauge Image Analysis software; VISIONx Inc, Pointe Claire, Quebec, Canada). Images of spinal cord sections were captured and digitized. Gray matter was outlined in the VisionGauge system, and background staining thresholds were calculated in adjacent white matter tissue for each section. The percentage of gray matter tissue staining positively above background thresholds were then calculated by the VisionGauge software. The mean percentage of MAP-2 gray matter staining was thus calculated for each animal.

\section{Statistics}

The statistics were analyzed by our statistician, who used analysis of variance with Bonferroni multiple comparison tests to determine significant differences. A nonparametric analysis provided the same conclusions as the analysis of variance.

\section{Results \\ Hind Limb Function}

Functional outcomes, quantified by Tarlov scores, showed a trend toward preservation in ATL compared with IR ani- 


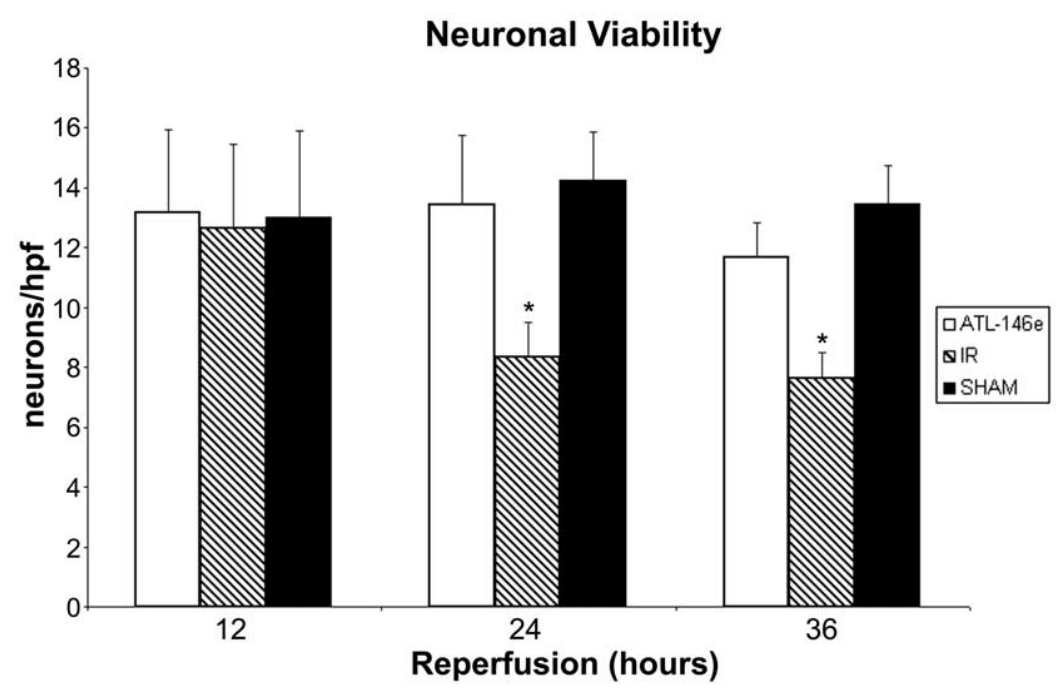

Figure 4. Neuronal viability of spinal cord motor neurons (viable neurons per high-powered field [hpf] among the ATL-146e, sham, and ischemia/reperfusion (IR) groups over the first 48 hours of reperfusion. ${ }^{*} \boldsymbol{P}<.05$ compared with both sham and ATL.

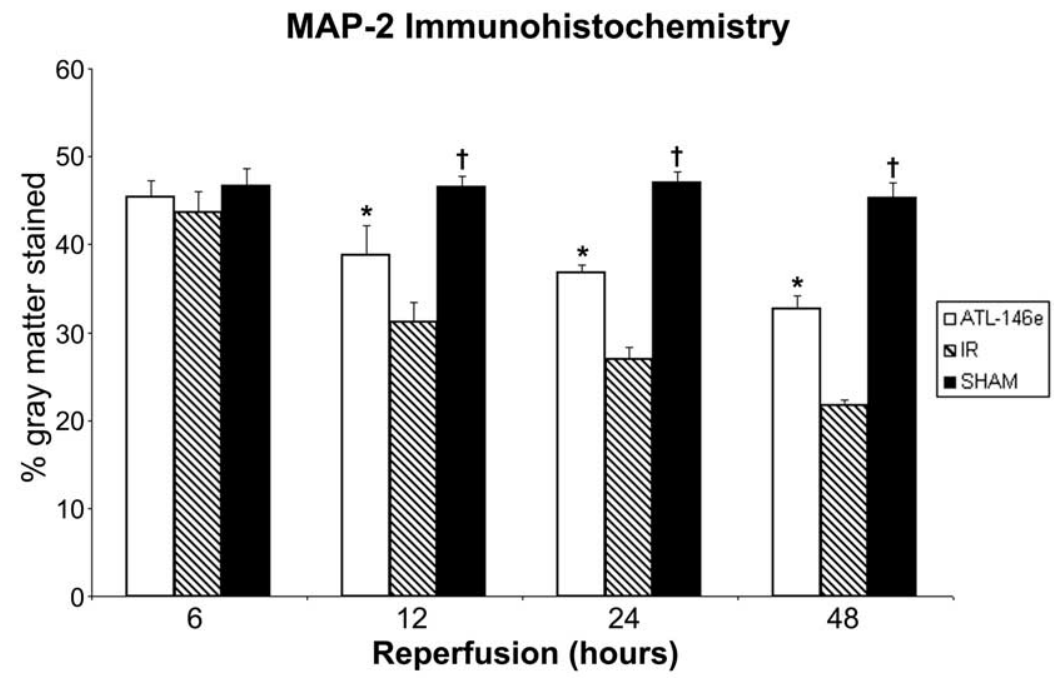

Figure 5. Microtubule-associated protein-2 (MAP-2) expression in gray matter (percentage area of gray matter stained) over the first 48 hours of reperfusion. $† P<.05$ compared with both $A T L$ and ischemia/reperfusion (IR); * $P$ $<.05$ compared with IR.

mals at 12 hours, and this became significant by 24 hours and continued to be significant at 36 and 48 hours. Figure 1 depicts functional outcomes in the first 48 hours. The mean Tarlov scores of the long-term survivors remained stable over 7 days as follows: day $1,4.25 \pm 0.48$; day $2,4.75 \pm$ 0.25 ; day $3,4.75 \pm 0.25$; day $4,4.75 \pm 0.25$; day $5,4.75 \pm$ 0.25 ; day $6,4.75 \pm 0.25$; and day $7,4.75 \pm 0.25$.

\section{Neutrophil Sequestration}

The spinal cord MPO assay demonstrated no differences in neutrophil sequestration among groups at 12 hours. By
24 and 48 hours, however, the MPO was significantly lower in sham and ATL animals compared with IR animals (Figure 2).

\section{TNF- $\alpha$}

Serum and CSF concentrations of TNF- $\alpha$ remained below the reliably detectable limits of the ELISA preparation. Although a significantly different bimodal peak of TNF- $\alpha$ in these compartments was noted in the IR group, the implications of these findings can only be speculated at such low levels. 
In spinal cord tissue depicted in Figure 3, TNF- $\alpha$ concentrations were similarly low at reperfusion and 3 hours later among all 3 groups. By 6 hours after reperfusion, spinal cord TNF- $\alpha$ in sham and ATL animals remained low, with significantly higher levels in IR animals. At 12 hours, the spinal cord TNF- $\alpha$ concentration leveled off in IR animals, only to peak again at 24 hours in all 3 groups.

\section{Neuronal Viability}

Spinal cord tissue from sham animals demonstrated normal gray and white matter cytoarchitecture, with large pyramidal ventral horn motor nuclei and prominent nucleoli. Tissue from ATL-treated animals demonstrated mild cytoarchitectural derangement, whereas IR animals had markedly abnormal spinal cords with vacuolization of parenchyma and multiple pyknotic neuronal somata.

Neuronal viability demonstrated no significant differences among groups at 12 hours of reperfusion. By 24 hours of reperfusion, significantly fewer viable neurons per highpower field were noted in IR animals compared with the sham and ATL groups. By 48 hours of reperfusion, neuronal viability deteriorated in the IR group compared with the other 2 groups. Neuronal viability, assessed by neurons per high-power field in ventral horn gray matter, in the first 48 hours is shown in Figure 4.

\section{MAP-2 Immunohistochemistry}

After 6 hours of reperfusion, the MAP-2 expression (percentage stained in gray matter) remained nearly identical among the 3 groups. By 12 hours, IR animals had significantly less MAP-2 expression compared with sham, but they were still not different from the ATL animals. By 24 hours of reperfusion, MAP-2 expression was significantly different among all 3 groups. At 48 hours, MAP-2 expression was again significantly different among all 3 groups. MAP-2 expression in the first 48 hours is shown in Figure 5.

\section{Discussion}

Various pharmacologic agents have been studied with the goal of attenuating ischemic spinal cord injury, but their utility in patients remains controversial. ${ }^{2}$ Improved understanding about injury progression and the role of inflammation in this process would permit the identification of novel strategies to limit IR injury. Our laboratory has demonstrated a potential therapeutic benefit of adenosine in this context. $^{10,12}$ However, adenosine requires a hypothermic carrier and local delivery, which restricts its use. ${ }^{13}$

Improved understanding of the mechanism of action of adenosine has elucidated the role of specific adenosine receptors. Systemic adenosine $\mathrm{A}_{2 \mathrm{~A}}$ receptor activation has attenuated injury in a rabbit model of spinal cord ischemia. ${ }^{7}$ This study demonstrates the attenuation of injury progression by adenosine $A_{2 A}$ receptor activation from 3 different perspectives of IR injury in the spinal cord. Tarlov scores were used to evaluate and follow up functional impairment. Neuronal cytoarchitecture was observed by using both neuronal viability scoring and the extent of MAP-2 expression. Finally, inflammation was assessed both by observing TNF- $\alpha$ in systemic, regional, and local compartments and by evaluating neutrophil sequestration in spinal cord tissue. Evaluation of these variables over time provides important insights into the interplay among these factors in both the progression and prevention of spinal cord IR injury.

The trend toward functional preservation with ATL therapy became statistically significant at 24 hours of reperfusion, at which time both sham and ATL animals had higher Tarlov scores than IR animals. This difference was sustained at 48 hours after reperfusion. The ATL group observed with longer evaluation preserved their 24-hour functional scores through 7 days, indicating that no deterioration of motor function arose subacutely among treated animals.

The study also demonstrated differences among groups in the progression of cytoarchitectural injury. Although differences in MAP-2 became notable by 12 hours after reperfusion between 2 of the groups, the differences in MAP-2 expression between the IR group and the other 2 groups did not become significant until 24 hours after reperfusion. By 48 hours after reperfusion, significant differences arose among all 3 groups, including significant differences between the sham group and the ATL group. Neuronal viability became significant after 24 hours of reperfusion between the IR group and the other 2 groups, and this continued through 48 hours after reperfusion. These findings demonstrate that histologic and immunohistochemical evidence of injury is not immediate and is preceded by detectable differences in motor functioning.

By comparing the inflammatory response to IR injury in other organ systems with the results of this study, interesting parallels are identified. ${ }^{14}$ Cassada and colleagues ${ }^{8}$ demonstrated reduced serum TNF- $\alpha$ concentrations by adenosine $\mathrm{A}_{2 \mathrm{~A}}$ receptor activation after temporary aortic occlusion in rabbits. The current study expanded on this finding by evaluating local, regional, and systemic inflammatory responses to spinal cord IR injury. Our current study did not demonstrate appreciable concentrations of TNF- $\alpha$ in serum or CSF to allow speculation about the systemic - or even regional-inflammatory response to this injury. The higher tissue concentrations showed a similar pattern that suggested a bimodal release of TNF- $\alpha$ after IR. Spinal cord tissue from the IR group demonstrated a significant increase in tissue TNF- $\alpha$ by 6 hours of reperfusion compared with the ATL and sham groups. Although IR spinal cord tissue TNF- $\alpha$ levels seemed to plateau after 12 hours of reperfusion, by 24 hours after reperfusion, the level peaked at a higher concentration in all 3 groups, which was significantly higher in IR animals compared with ATL and sham animals. 
This bimodal peak in tissue TNF- $\alpha$ concentration was not predicted, but similar observations have been made at earlier time points in pulmonary IR injury. ${ }^{15-17}$ These studies concluded that the resident macrophages were responsible for early inflammation, which is followed with more vigor by the neutrophil response to the IR injury. Because the spinal cord harbors no resident leukocytes, the early peak in tissue TNF- $\alpha$ in our study may derive from microglia, which precipitate the neutrophil response and lead to amplification of inflammation after 24 hours of reperfusion. This did coincide with the significant increase in neutrophil sequestration in the IR group. This finding supports the conclusion from other organ models of IR that describe early local cellular inflammation trailed by a later, more intense neutrophil-derived inflammatory response.

This study demonstrated that ATL-146e attenuated the inflammatory response to IR in the spinal cord, but it did not identify the attenuating mechanism. The study demonstrated both inflammatory attenuation and functional preservation, but the exact relationship between the 2 remains unknown. The study does not exclude the possibility that inflammation is impaired by adenosine $\mathrm{A}_{2 \mathrm{~A}}$ receptor activation because of direct neuroprotective effects that limit initial spinal cord neuronal injury. Other authors have argued that early intervention remains the best chance for functional preservation after spinal cord injury in both vascular surgery and blunt spinal cord trauma. ${ }^{18}$ The benefit of pharmacologic protection with ATL-146e may be optimized with the initiation of therapy at reperfusion. Preventive strategies are already being exploited with lumbar CSF drainage, regional cooling, and distal perfusion techniques. ${ }^{19-21}$ ATL-146e clearly preserves spinal cord function and neuronal cytoarchitecture and attenuates the inflammatory response after IR. The protective mechanisms are not fully understood, but animals maintain function despite ischemic insult.

In conclusion, this study demonstrated optimal time points for studies of differences in function, inflammation, and neuronal cytoarchitecture. Most notably in this study and in patients undergoing transient thoracic aortic occlusion who might avoid distal bypass or lumbar drain placement, adenosine $A_{2 A}$ receptor activation attenuates every aspect of injury measured, including markers of hind limb function, neuronal cytoarchitecture, and inflammation.

We thank Tony Herring, Cindy Dodson, and Sheila Hammond for their invaluable technical assistance during this study. We also thank Jayson Reiger of Adenosine Therapeutics for providing us with the ATL-146e used in this study. Dr Kron and Dr Linden have a relationship with Adenosine Therapeutics, LLC, which owns the rights to ATL-146e.

\section{References}

1. Gharagozloo F, Neville RF Jr, Cox JL. Spinal cord protection during surgical procedures on the descending thoracic and thoracoabdominal aorta: a critical overview. Semin Thorac Cardiovasc Surg. 1998;10:73-86.

2. Reece TB, Kern JA, Tribble CG, Cassada DC. The role of pharmacology in spinal cord protection during thoracic aortic reconstruction. Semin Thorac Cardiovasc Surg. 2003;15:365-77.

3. Schwab ME, Bartholdi D. Degeneration and regeneration of axons in the lesioned spinal cord. Physiol Rev. 1996;76:319-70.

4. Cassada DC, Tribble CG, Laubach VE, Nguyen BN, Rieger JM, Linden J, et al. An adenosine A2A agonist, ATL-146e, reduces paralysis and apoptosis during rabbit spinal cord reperfusion. J Vasc Surg. 2001;34:482-8.

5. Cassada DC, Tribble CG, Kaza AK, Fiser SM, Long SM, Linden J, et al. Adenosine analogue reduces spinal cord reperfusion injury in a time-dependent fashion. Surgery. 2001;130:230-5.

6. Cassada DC, Tribble CG, Long SM, Kaza AK, Linden J, Rieger JM, et al. Adenosine A2A agonist reduces paralysis after spinal cord ischemia: correlation with $\mathrm{A} 2 \mathrm{~A}$ receptor expression on motor neurons. Ann Thorac Surg. 2002;74:846-9.

7. Cassada DC, Gangemi JJ, Rieger JM, Linden J, Kaza AK, Long SM, et al. Systemic adenosine A2A agonist ameliorates ischemic reperfusion injury in the rabbit spinal cord. Ann Thorac Surg. 2001;72:1245-50.

8. Cassada DC, Tribble CG, Long SM, Laubach VE, Kaza AK, Linden J, et al. Adenosine A2A analogue ATL-146e reduces systemic tumor necrosing factor-alpha and spinal cord capillary platelet-endothelial cell adhesion molecule-1 expression after spinal cord ischemia. $J$ Vasc Surg. 2002;35:994-8.

9. Lang-Lazdunski L, Heurteaux C, Dupont H, Widmann C, Lazdunski M. Prevention of ischemic spinal cord injury: comparative effects of magnesium sulfate and riluzole. J Vasc Surg. 2000;32:179-89.

10. Herold JA, Kron IL, Langenburg SE, Blackbourne LH, Tribble CG. Complete prevention of postischemic spinal cord injury by means of regional infusion with hypothermic saline and adenosine. $J$ Thorac Cardiovasc Surg. 1994;107:536-41.

11. Stone JR, Walker SA, Povlishock JT. The visualization of a new class of traumatically injured axons through the use of a modified method of microwave antigen retrieval. Acta Neuropathol. 1999;97:335-45.

12. Seibel PS, Theodore P, Kron IL, Tribble CG. Regional adenosine attenuates postischemic spinal cord injury. J Vasc Surg. 1993;18: 153-8; discussion 158-60

13. Ross SD, Kern JA, Gangemi JJ, St Laurent CR, Shockey KS, Kron IL, et al. Hypothermic retrograde venous perfusion with adenosine cools the spinal cord and reduces the risk of paraplegia after thoracic aortic clamping. J Thorac Cardiovasc Surg. 2000;119:588-95.

14. Sullivan GW, Rieger JM, Scheld WM, Macdonald TL, Linden J. Cyclic AMP-dependent inhibition of human neutrophil oxidative activity by substituted 2-propynylcyclohexyl adenosine $\mathrm{A}(2 \mathrm{~A})$ receptor agonists. Br J Pharmacol. 2001;132:1017-26.

15. Fiser SM, Tribble CG, Long SM, Kaza AK, Cope JT, Laubach VE, et al. Lung transplant reperfusion injury involves pulmonary macrophages and circulating leukocytes in a biphasic response. $J$ Thorac Cardiovasc Surg. 2001;121:1069-75.

16. Fiser SM, Tribble CG, Long SM, Kaza AK, Kern JA, Kron IL. Pulmonary macrophages are involved in reperfusion injury after lung transplantation. Ann Thorac Surg. 2001;71:1134-8.

17. Maxey TS, Enelow RI, Gaston B, Kron IL, Laubach VE, Doctor A. Tumor necrosis factor-alpha from resident lung cells is a key initiating factor in pulmonary ischemia-reperfusion injury. J Thorac Cardiovasc Surg. 2004;127:541-7.

18. Bracken MB. Methylprednisolone and acute spinal cord injury: an update of the randomized evidence. Spine. 2001;26:S47-54.

19. Coselli JS, LeMaire SA. Left heart bypass reduces paraplegia rates after thoracoabdominal aortic aneurysm repair. Ann Thorac Surg. 1999;67:1931-4; discussion 1953-8.

20. Coselli JS, LeMaire SA, Schmittling ZC, Koksoy C. Cerebrospinal fluid drainage in thoracoabdominal aortic surgery. Semin Vasc Surg. 2000;13:308-14.

21. Cambria RP, Davison JK. Regional hypothermia with epidural cooling for spinal cord protection during thoracoabdominal aneurysm repair. Semin Vasc Surg. 2000;13:315-24. 


\section{Discussion}

Dr Robert C. Robbins (Stanford, Calif). Can you tell me what these animals look like? I am not familiar with this Tarlov score, so can these pigs walk, or are they a little bit weaker than the others?

Dr Reece. The Tarlov score ranges from 0 to 5. So 0 means complete hind limb paralysis; 1 indicates some hind limb movement; 2 means that the animal can sit when placed in a sitting position; 3 means that it can sit without assistance; 4 indicates an unsteady gait; and 5 indicates a normal gait.

Dr Ross M. Ungerleider (Portland, Ore). Let me just be clear about this. You had a 30-minute ligation, or ischemic injury?

Dr Reece. Yes, sir.

Dr Ungerleider. And ATL was given before that, 10 minutes before and then for 3 hours?

Dr Reece. Correct.

Dr Ungerleider. Are you postulating that there is some sort of inflammatory process that is caused by the ischemic injury and that this is the mechanism?

Dr Reece. I think that if you had asked me that when we started working with ATl-146e, I would have agreed wholeheartedly that inflammatory inhibition was the mechanism of protection from ischemic injury in this model. However, the more that we learn about this compound, the more it seems that we are attenuating the injury directly. This study in particular demonstrates that none of the inflammatory markers is actually becoming significantly different until after the function has been altered by the injury. So we would postulate that we are attenuating the injury and that there is then an inflammatory response to the injury itself which is also attenuated.

Dr Robbins. Where does this compound stand in development? Is it being given clinically for any other indication?

Dr Reece. Right now it is being given in patients for coronary angiography at much higher doses, but we have not yet used it for injury attenuation in patients.

Dr Robbins. If it is available to be used in patients with aortic surgery, do you have any plans to do a clinical study using this?

Dr Reece. We are pursuing a clinical study, but we are pushing to study ATL-146e in patients who have sustained blunt spinal trauma, to recruit a higher volume of patients and with more statistical potential for injury attenuation.

Dr Ungerleider. I presume that your hemodynamics of the animals are the same in all groups: temperatures are the same?

Dr Reece. Correct. The temperatures were monitored with a rectal probe and adjusted with a heating pad. We have never seen any hemodynamic differences with this dosage of ATL-146e in any of our models of ischemia/reperfusion injury.

Dr Carmelo A. Milano (Durham, NC). I was going to ask the same thing Ross just mentioned. I think that when you present these data, it is important to show the hemodynamics, because this is a potentially hemodynamically significant agent that you are giving, and during the period of ischemia there is presumably some limited collateral perfusion. So when you show the data, I think it is important to document or to demonstrate that the hemodynamics are equivalent in the 2 groups, because that will certainly affect the collateral circulation.

\section{Bound volumes available to subscribers}

Bound volumes of The Journal of Thoracic and Cardiovascular Surgery are available to subscribers (only) for the 2004 issues from the Publisher, at a cost of $\$ 134.00$ for domestic, $\$ 165.85$ for Canadian, and $\$ 155.00$ for international subscribers for Vol 127 (January-June) and Vol 128 (July-December). Shipping charges are included. Each bound volume contains a subject and author index.

The binding is durable buckram with the Journal name, volume number, and year stamped in gold on the spine. Payment must accompany all orders. Contact Elsevier Inc., Subscription Customer Service, 6277 Sea Harbor Dr, Orlando, FL 32887, USA; phone 800-654-2452 or 407-345-4000.

Subscriptions must be in force to qualify. Bound volumes are not available in place of a regular Journal subscription. 